Article

\title{
SPOT-Based Sub-Field Level Monitoring of Vegetation Cover Dynamics: A Case of Irrigated Croplands
}

\author{
Olena Dubovyk ${ }^{1, *}$, Gunter Menz ${ }^{1,2}$, Alexander Lee ${ }^{3}$, Juergen Schellberg ${ }^{1,4}$, Frank Thonfeld ${ }^{1,2}$ \\ and Asia Khamzina 5
}

1 Center for Remote Sensing of Land Surfaces (ZFL), University of Bonn, Bonn 53113, Germany;

2 Remote Sensing Research Group, Department of Geography, University of Bonn, Bonn 53115, Germany; E-Mails: g.menz@geographie.uni-bonn.de (G.M.); frank.thonfeld@uni-bonn.de (F.T.)

3 Khorezm Rural Advisory Support Service (KRASS), Urgench 220100, Uzbekistan;

E-Mail: 1i_sasha@mail.ru

4 Institute of Crop Science and Resource Conservation (INRES), University of Bonn, Bonn 53115, Germany; Email: j.schellberg@uni-bonn.de

5 Center for Development Research (ZEF), University of Bonn, Bonn 53113, Germany; E-Mail: asia.khamzina@uni-bonn.de

* Author to whom correspondence should be addressed; E-Mail: odubovyk@uni-bonn.de; Tel.: +49-0228-732-092; Fax: +49-0228-736-857.

Academic Editors: Arnon Karnieli and Prasad S. Thenkabail

Received: 21 January 2015 / Accepted: 12 May 2015 / Published: 26 May 2015

\begin{abstract}
Acquiring multi-temporal spatial information on vegetation condition at scales appropriate for site-specific agricultural management is often complicated by the need for meticulous field measurements. Understanding spatial/temporal crop cover heterogeneity within irrigated croplands may support sustainable land use, specifically in areas affected by land degradation due to secondary soil salinization. This study demonstrates the use of multi-temporal, high spatial resolution $(10 \mathrm{~m})$ SPOT-4/5 image data in an integrated change vector analysis and spectral mixture analysis (CVA-SMA) procedure. This procedure was implemented with the principal objective of mapping sub-field vegetation cover dynamics in irrigated lowland areas within the lowerlands of the Amu Darya River. CVA intensity and direction were calculated separately for the periods of 1998-2006 and 2006-2010. Cumulative change intensity and the overall directional trend were also derived for the entire observation period of 1998-2010. Results show that most of the vector changes were observed between 1998 and 2006; persistent conditions were seen within the study region
\end{abstract}


during the 2006-2010 period. A decreasing vegetation cover trend was identified within $38 \%$ of arable land. Areas of decreasing vegetation cover were located principally in the irrigation system periphery where deficient water supply and low soil quality lead to substandard crop development. During the 2006-2010 timeframe, degraded crop cover conditions persisted in $37 \%$ of arable land. Vegetation cover increased in $25 \%$ of the arable land where irrigation water supply was adequate. This high sub-field crop performance spatial heterogeneity clearly indicates that current land management practices are inefficient. Such information can provide the basis for implementing and adapting irrigation applications and salt leaching techniques to site-specific conditions and thereby make a significant contribution to sustainable regional land management.

Keywords: change vector analysis; spectral unmixing; land degradation; site specific management; Uzbekistan

\section{Introduction}

The Central Asian countries of Kazakhstan, Kyrgyzstan, Tajikistan, Turkmenistan and Uzbekistan are all strongly affected by the ongoing process of land degradation (LD). LD negatively impacts crop and livestock productivity, agricultural incomes, and the livelihoods of rural populations. The principal cause of cropland degradation within irrigated agricultural areas of these countries are inefficient irrigation and drainage practices that result in elevated groundwater tables which, in turn, leads to soil salinization and declining crop yields [1-3]. This problem is acute in Uzbekistan, where approximately 30,000 ha of croplands are lost every year to excessive salt and waterlogging and $53 \%$ of the irrigated area is affected in some degree by soil salinity. Crop cultivation brings little or no profit in these areas [4]. In order to improve the efficiency of land rehabilitation and impact assessment measures, land managers require spatially explicit and timely information on land conditions [5]. Remote sensing techniques have been successfully applied at various spatial scales to assemble such information [6,7].

Very few spatially explicit LD assessments have been performed at regional or national scales in Central Asia. More attention has been paid to analyses of land-use and land-cover (LULC) changes in the region [8-10]. For example, spatial and temporal LD patterns were analyzed over the Ust-Urt Plateau in Kazakhstan using Landsat images and geostatistical methods [11]. Inter-annual changes in vegetation dynamics and their relationship to temperature and precipitation conditions in Central Asia were studied for the 1982-2003 period by Propastin et al. [12]. De Beurs and Henebry [13] assessed LULC changes in Kazakhstan during the periods of 1985-1988 and 1995-1999 using a normalized difference vegetation index (NDVI) satellite time series derived from Advanced Very High Resolution Radiometer (AVHRR) data.

LD trends in irrigated croplands were assessed in the lower Amu Darya River Basin, which is among the most salt-affected regions in Central Asia. Previous analyses have determined that land productivity decline has affected 94,835 ha (approximately 20\%) of the arable land in this region. These figures have been calculated through use of a $250 \mathrm{~m}$ Moderate Resolution Imaging Spectroradiometer (MODIS) NDVI time series [14] as well as through use of indices derived from a Medium Resolution Imaging Spectrometer (MERIS) dataset [15]. Le et al. [16] indicated a similar proportion of degraded croplands 
(26\%) in Uzbekistan based on the spatial trend analysis of an 8km AVHRR NDVI time series covering the period of 1982-2006. These assessments reveal broad regional patterns and declining trends in cropland productivity. Soil salinity and its impacts on crop performance, land rehabilitation and management planning are highly spatially and temporally variable. Detailed, site-specific information derived from very high spatial resolution imagery can be of significant benefit in analyzing these phenomena and understanding this variability [17].

Gradual vegetation cover loss over time serves as an indication of biomass productivity decline and is often used as a proxy for LD [18]. Among a variety of existing methods, statistical trend analysis of vegetation index time series are, therefore, most commonly used for satellite-based LD assessment $[6,19,20]$. Trend analyses are most often applied to coarse scale imagery (such as AVHRR); use of fine scale imagery (e.g., Landsat) is less frequent [21]. High spatial resolution Landsat time series are required for field level assessments; however, such data are not yet available at the required temporal density for all geographic locations [22]. This prevents monitoring of LD at local scales as well as implementation of site-specific management actions.

Alternative methods should be developed and implemented that would allow derivation of spatial information to identify and locate areas of crop cover damage and/or degradation at the level of individual agricultural fields [23]. One promising approach is based on the use of change vector analysis (CVA) [24]. CVA is a multispectral change detection technique effective in monitoring land cover and condition [25]. CVA uses as inputs two or more features associated with a given image pixel. These may include image spectral bands or their derivatives along with specific biophysical parameters, which allow for mapping of change direction and magnitude [26]. This method offers two principal advantages: it enables detection of gradual land cover changes, and it allows concurrent analyses of a given change in all data layers, rather than focusing on a few selected bands [27]. Although the utility of this technique has been clearly demonstrated [28], few studies currently exist documenting the use of CVA for assessment of land conditions in arid/drylands regions, even with the inclusion of high spatial resolution image data. Additionally, the potential of combining CVA with high spatial resolution imagery and sub-pixel mapping techniques to improve discrimination of land cover dynamics remains to be investigated [29].

This research follows the previous study described in Dubovyk et al. [23] in which an object-based CVA approach was proposed for detecting crop cover changes at a field level within irrigated agro-ecosystems. The main aim of this study is on the use of high spatial resolution satellite imagery to map sub-field crop cover dynamics within irrigated drylands areas in Uzbekistan. It was hypothesized that, in the study area:

- Spatiotemporal patterns of crop cover dynamics within and between the agricultural fields can be detected by the analysis of multitemporal $10 \mathrm{~m}$ SPOT data.

- The combined CVA-SMA procedure is suitable to monitor land conditions in irrigated croplands.

- The derived spatial information could be used to assist cropland management decisions.

\section{Study Area}

The study area includes the southern part of the Autonomous Republic of Karakalpakstan (SKKP), which is located in northwestern Uzbekistan (Figure 1). This area lies approximately $200 \mathrm{~km}$ south of 
the former shore of the Aral Sea and extends between latitude $40^{\circ} 62^{\prime} \mathrm{N}$ and $42^{\circ} 71 \mathrm{~N}$ and longitude $60^{\circ} 02^{\prime} \mathrm{E}$ and $62^{\circ} 44^{\prime} \mathrm{E}$. The region includes 140,000 ha of arable irrigated land [15].
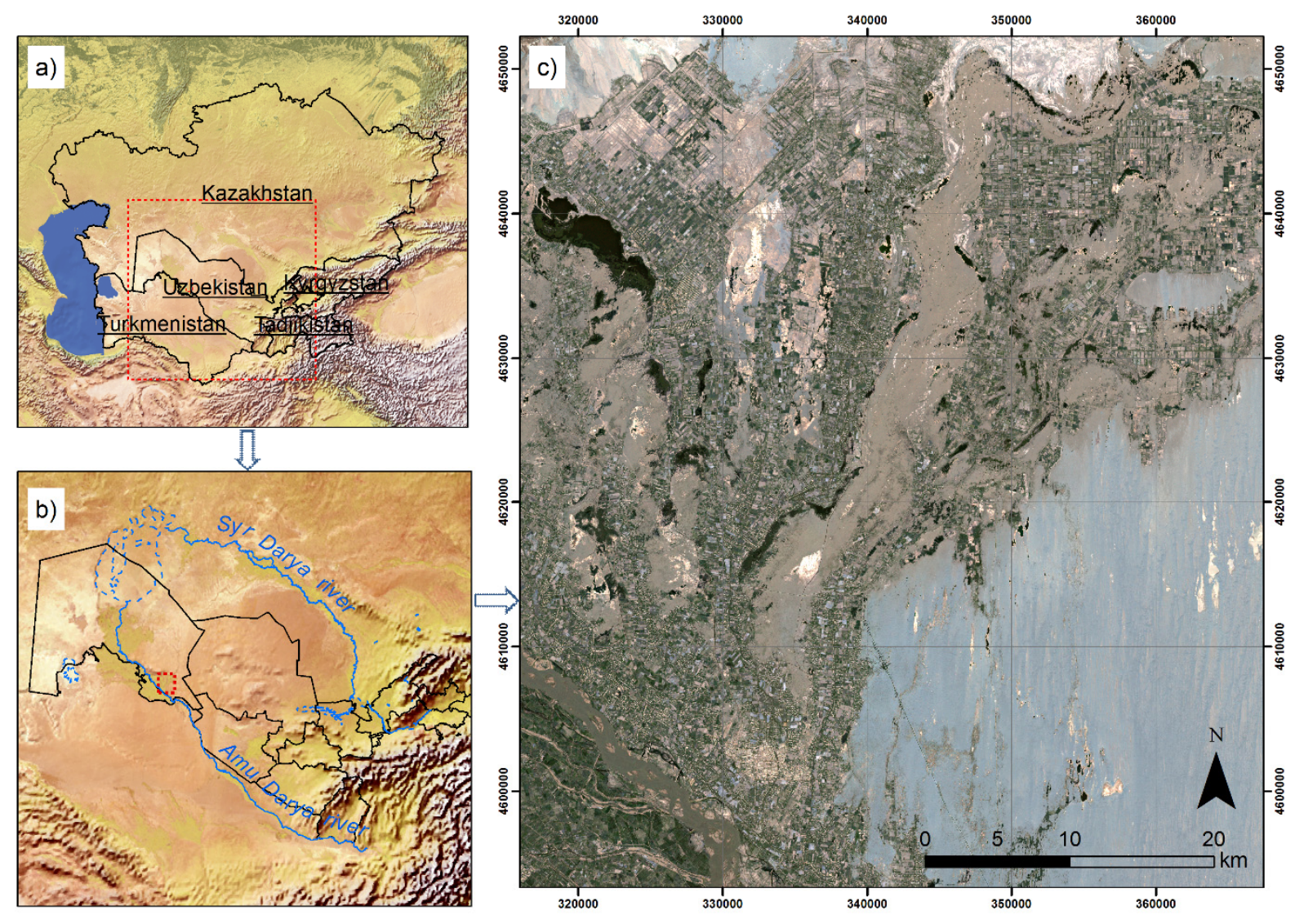

Figure 1. Location of the study area, (a) in Central Asia, (b) in Uzbekistan and (c) study area in the south-eastern part of Autonomous Republic of Karakalpakstan. The SPOT image (acquired 13 August 2010) provides background image in (c).

The study region is a part of the Central Asian semi-desert climate zone and is characterized by an extreme continental climate [30]. Annual precipitation averages $100 \mathrm{~mm}$ and generally occurs outside the April-October crop growing season [31]. Crop production in the region is dependent entirely on irrigation water from the Amu Darya River distributed through a dense network of irrigation canals and drains (Figure 1). The main crops are cotton and winter wheat, grown under a system of state direction. This system defines specific areas for cotton cropping and establishes yield targets for both crops according to cropland productivity characteristics. Typically, $50 \%$ to $70 \%$ of the arable land is allocated to cotton production and $20 \%$ to $30 \%$ is in winter wheat [32]. These cropping areas are prioritized for water allocation and procurement of other agricultural inputs. Annual nitrogen fertilizer inputs are substantial for both crops, ranging from $200-250 \mathrm{~kg} \cdot \mathrm{ha}^{-1}$ for wheat and $160-180 \mathrm{~kg} \cdot \mathrm{ha}^{-1}$ for cotton, and is typically applied several times during the growing season [1]. On land that is not under cotton or wheat, paddy rice, maize, sorghum, melons, sunflowers, and vegetables are grown [9]. Irrigation water is supplied to individual fields according to standard guidelines established for large-scale farming units during the Soviet era [33]. Irrigation allocations are influenced by seasonal water availability, which is significantly decreased during drought years. 
Irrigation has been ongoing in the region for decades characterized by insufficient natural and engineered drainage. This has caused elevated groundwater tables and enhanced capillary rise during the crop growing season. Resultant secondary soil salinization can be observed in irrigated croplands throughout the entire region [34]. Adverse impacts of soil and groundwater salinity on crop yields, as well as land abandonment due to LD are increasingly common in the study region. In an effort to control the increased salinity, annual water application prior to the April-October cropping season is practiced to leach salts down to lower levels within the soil profile. The drainage water from this process is then conveyed outside the cropland area through a network of drainage collectors. Land leveling is also essential in order to decrease local micro-relief variability and assure homogeneous water distribution throughout the fields for effective salt management.

\section{Datasets}

\subsection{Satellite Imagery}

These analyses are based on high resolution Satellite Pour l'Observation de la Terre (SPOT) Level 1B imagery recorded in 1998, 2006 and 2010 (Table 1). We used the SPOT-5 multispectral data at the standard $10 \mathrm{~m}$ spatial resolution; the SPOT-4 multispectral data were pan-sharpened by the image provider to $10 \mathrm{~m}$ resolution using a High Pass Filter algorithm [35].

Table 1. Selected SPOT images covering southern Karakalpakstan in three time steps.

\begin{tabular}{ccc}
\hline Sensor & Acquisition Date & Denoted in Text \\
\hline SPOT-4 & 11 July 1998 & 1998 \\
SPOT-5 & 27 July 2006 & 2006 \\
SPOT-5 & 13 August 2010 & 2010 \\
\hline
\end{tabular}

All images were co-registered utilizing approximately 450 tie points per image, selected via an automated point matching algorithm [36]. The image co-registration procedure resulted in an overall positional error of less than 0.5 pixel. Atmospheric correction was performed using the ATCOR2 (Version 10) software [37]. For CVA and SMA, data quality and image radiometric normalization impacts the change detection results, as both methods require radiometric similarity among multitemporal images [27]. All images were, therefore, radiometrically normalized using the Iteratively Re-weighted Multivariate Alteration Detection transformation [38].

Because crop growth is directly impacted by decreased water availability, a review of irrigation water statistics was made for the southern Karakalpakstan study area in order to identify years of comparable irrigation water supplies (Figure 2) [39]. The years 1998, 2006, and 2010 were selected for analyses. The choice of anniversary image acquisition dates, along with radiometric normalization of the image data minimized impacts of crop phenology and solar illumination conditions. 


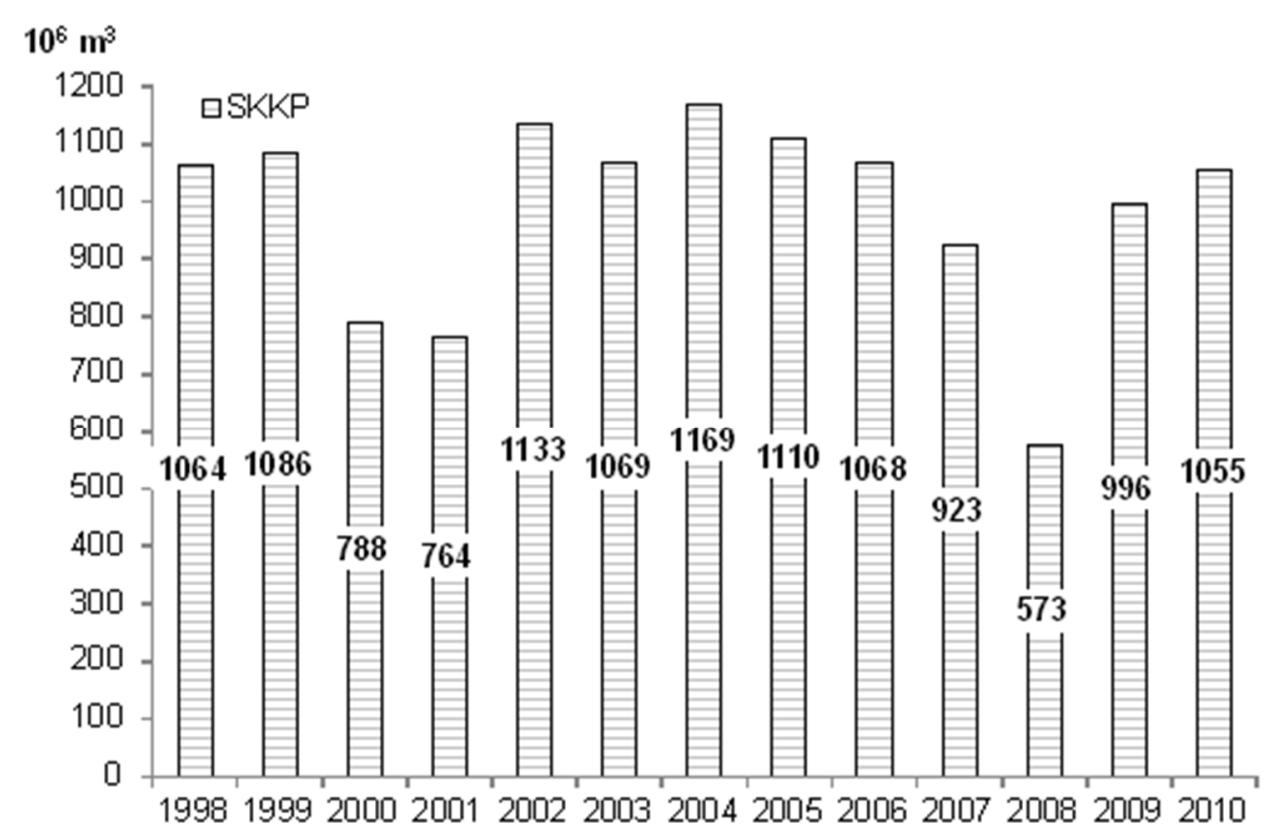

Figure 2. Total irrigation water use in southern Karakalpakstan during the vegetation periods of $1998-2010$.

\subsection{Ancillary Data}

We have applied the field boundary mask to focus our analysis only on cultivated areas. Current cadastral maps covering the study area were collected and digitized. This map set was acquired from the regional offices of the Uzbek State Committee on Land Resources, Geodesy, Cartography and State Cadaster. Agricultural field boundaries were initially assumed to be identical in 1998, 2006 and 2010. This was verified by local cadastral experts and by a visual assessment of the satellite images. This conclusion is further sustained by the agricultural structure in place in the region: A state-driven, area-based crop cultivation system that is wholly reliant on the regional irrigation drainage infrastructure [40]. In our case, it was not necessary to apply image segmentation to derive field objects as a cadastral map was available. However, for the cases when the cadastral information is missing, segmentation can be used to derive objects that match field parcels [41].

The following map sets were used to evaluate and interpret the output change maps:

- an LD trend map calculated from a $250 \mathrm{~m}$ resolution MODIS time series covering the 2000-2010 period [14];

- a vegetation cover map and agricultural land use maps for 1998 and 2010 compiled using $30 \mathrm{~m}$ Landsat imagery [23].

\section{Methodology}

\subsection{Spectral Mixture Analysis}

Spectral mixture analysis (SMA) provides an accurate quantitative estimate of land covers at a sub-pixel level by decomposing the constituent ground cover components within a pixel [42]. Fractional images derived through SMA have been shown to be effective for detailed land cover monitoring 
(e.g., [29]) and were selected as input features for the CVA performed in this study. The spectral unmixing approach is preferred for precision agriculture applications, as it provides a powerful means of capturing the spectral variation within a field caused by the various target components such as soil and vegetation [43].

As an input for the SMA, reference spectra or endmembers can be derived from spectral libraries [44], field spectra [45], the imagery itself [46], or simulated using radiative transfer models [47]. In this study, reference spectra (or endmembers) for the SMA was derived from the imagery itself [46] by the measuring extracted spectra at the identical scale as the remote sensing data [48]. In order to include only cropping areas in our analysis, a cadastral field boundary mask was used. A Minimum Noise Fraction (MNF) transform [49] was applied to the 2010 image to determine the inherent data dimensionality and to isolate noise in the image data. The three bands of the MNF images that contained the highest eigenvalues were then used to derive the endmembers by calculating the pixel purity index [50].

A linear constrained unmixing model was used to derive the fraction images for the three endmembers of vegetation (VT), soil (SL), and water [51]. The endmember model derived from the 2010 image was applied to all other images to ensure consistent estimates of the fractional covers and direct comparison of the fraction images [52]. Direct comparison of these images is important to determine the accuracy of change detection [53]. The accuracy of SMA is often quantified based on the fit between the modeled and observed mixed spectral signals. Model fit can be assessed by an error metric such as the Root Mean Square error (RMSE) [54] or by analyzing histograms of the fraction images [55]. In this study, the fit of the spectral unmixing model was assessed by calculating the root mean square error (RMSE) and analyzing histograms of the fraction images.

\subsection{Change Vector Analysis}

CVA allows the determination of change vector magnitude, or intensity, as well as change direction between two or more steps in the time series. The change vector magnitude, $\Delta \mathrm{C}$ is calculated as the Euclidean distance of pixel spectra between two years in the feature space, the reference date $\left(\mathrm{T}_{1}\right)$ and the target date $\left(\mathrm{T}_{2}\right)$. In our case, the change magnitude is computed for the VT, SL and WT endmember metrics according to:

$$
\|\Delta C\|=\sqrt{\left(\mathrm{VT}_{\mathrm{T}_{1}}-\mathrm{VT}_{\mathrm{T}_{2}}\right)^{2}+\left(\mathrm{SL}_{\mathrm{T}_{1}}-\mathrm{SL}_{\mathrm{T}_{2}}\right)^{2}+\left(\mathrm{WT}_{\mathrm{T}_{1}}-\mathrm{WT}_{\mathrm{T}_{2}}\right)^{2}}
$$

A decision on change is made when the change magnitude exceeds a certain threshold that can be defined quantitatively or qualitatively [56]. A value of one standard deviation was selected for this threshold after evaluating a number of thresholding algorithms and analyses of image distributions $[25,57,58]$. The change images calculated using the one standard deviation threshold were plausible, reinforcing the validity of this threshold value.

Change direction was decided based on sector coding as more than two spectral dimensions were introduced into the CVA. The change category was identified using a combination of minus symbols ( - ) for decrease and plus symbols $(+)$ for increase of each metric [59]. A decrease in VT and increase in either or both SL and WT indicated a declined vegetation cover, whereas an increase in VT and decrease in either or both SL and WT signified increased vegetation cover. All other combinations of sector codes denoted increased, decreased or stable VT, SL and WT, indicating persisting land-cover conditions in a single time step. 
The cumulative change magnitude was calculated per pixel as a sum of absolute values of amplitudes from 1998 to 2010. The cumulative magnitude is an indicator for a mean variability of cropland cover within a pixel over the monitoring period. The overall change direction was derived based on the fraction metrics between the 2010 end and the 1998 beginning of the monitoring period, also using a sector coding approach. The overall change direction is an indication of the general trend for the cropland cover throughout the observation period.

\subsection{Evaluation and Interpretation of the CVA-SMA Results}

To assess the CVA-SMA performance specifically in relation to vegetation cover decrease detection, the overall change direction map compiled here was compared to a LD map produced in a previous study [14]. This map was derived from a 250 m MODIS NDVI time-series data (2000-2010) based on linear trend analysis and it consists of a "LD" class - indicating a significant negative vegetation trend - and an "other trends" class. The overall accuracy of this map was 68\% [14]. Two analogous classes from the current overall change map were directly compared: the "vegetation cover decrease" class and the "other" class. For this, the SPOT-based map was aggregated to the MODIS pixel size following [60]. The resampling was based on the majority rule assignment over the coarser grid cells. The maps were compared based on a random sample of 7503 pixels. The stratified weighted sampling was used that the share of samples of both classes in the number of all extracted samples was defined according to its percentage in the reference data set.

The overall change map was further correlated to an additional series of available land use maps. These maps indicate the distribution of uncropped and cultivated areas within each individual field for 1998 and 2010, as well as the types of cultivated crops growing in the fields in 2010. The map of 1998 has an overall accuracy of $93 \%$ [61], the crop distribution map of $2010-86 \%$ [62]. We derived cultivated and fallow land for 2010 from the crop distribution map by reclassifying the classes.

For cross comparison of these land use maps, an object-based overall change direction map was compiled for the 1998-2010 period. The object-based change image was derived followed the procedure described in Dubovyk et al. [23]. This map has the same classes as a pixel-based maps but calculated using the object-based approach, thus showing changes at a field parcel level. The same authors have proven that the produced change maps based on the CVA and SMA are robust to changes associated with changes in cropping patterns.

\section{Results and Discussion}

\subsection{Results of Spectral Mixture Analysis}

Three endmembers were manually selected from the 2010 image feature space and coded as follows:

- VT - associated with photosynthetically active vegetation within the crop fields;

- SL-representing bare soil patches in the fields;

- WT-referring mainly to waterlogged land.

The number of endmembers was constrained to three due to the SPOT data spectral dimensionality [63]. Shadow effects were generally not detectable within the fields as these effects are reduced within the flat field areas in the study region (where slope values typically are less than 10\%) and the fields are characterized by homogeneous or sparse canopies [64]. 
Low root-mean-square error (RMSE) values reinforce the validity of the SMA results (Figure 3). Examination of the residual bands also revealed no systematic patterns, and the fraction image histograms were found to lie within the 0 to 1 range. The obtained results are comparable with those by Dubovyk et al. [23,65] who derived a 4-member model (green vegetation, bright soil, dark soil and water) based on the Landsat TM images for the area covering SKKP and Khorezm province of Uzbekistan. These authors also found good correlation of the SMA with the reference data that yielded $\mathrm{R}^{2}$-value of 0.80 in the study region.
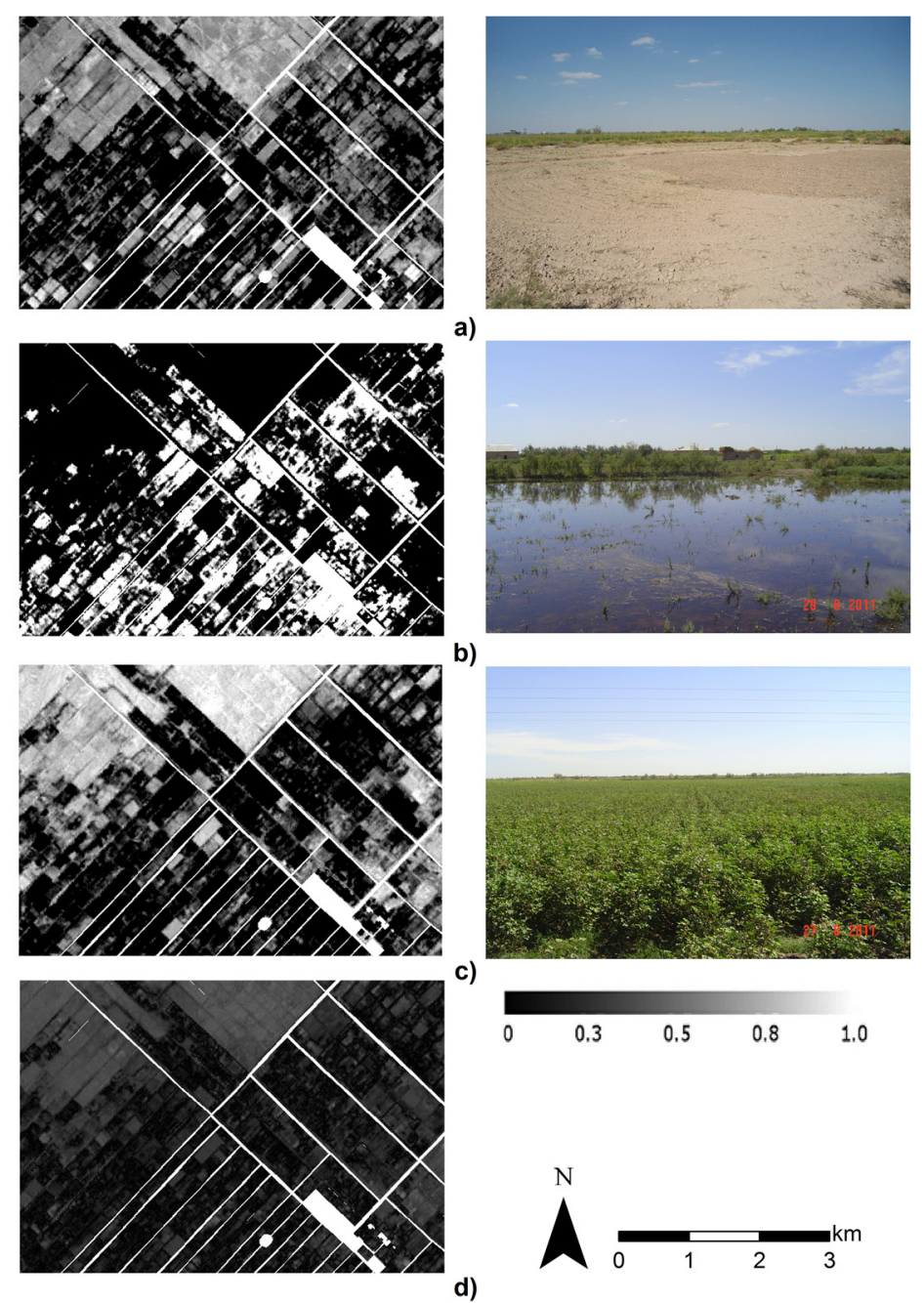

Figure 3. Subsets of fraction images derived from linear unmixing of the August 2010 SPOT-5 image and their corresponding land cover elements: (a) bare soil, (b) water surfaces, (c) photosynthetically active vegetation, (d) root mean square error.

\subsection{Vegetation Cover Changes in the Study Area}

The overall change map highlights general directional trends in vegetation cover change throughout the observation period. Vegetation cover trends in the study area were as follows: (1) vegetation cover decrease was detected on $38 \%$ of arable land; (2) vegetation conditions remained unchanged (persisted) on $37 \%$ of arable land, and; (3) vegetation cover increased on $25 \%$ of arable land (Table 2; Figure $4 a$ ). The majority of increased vegetation cover is found alongside the main irrigation channels and in fields located in close proximity to the Amu Darya River, in locations with better access to irrigation water supply [14]. 
Fields characterized by decreased vegetation cover cluster mainly in peripheral portions of the irrigation system as well as along the borders with the Kyzyl-Kum desert, to the north and east of the study region. Near the desert, impeded water supply and sandy soils with low water holding capacity produce poor crop development [15]. Due to marginal returns, farmers are less likely to cultivate such lands and they are often abandoned [66]. Comparison of the land-use maps confirmed this trend. The 19\% (7049 ha) of the cropland area with decreased vegetation cover was under cultivation in 1998 and left fallow in 2010 (Figure 5). A significant cluster of declining vegetation cover was also observed in the northwestern part of the SKKP, a region where the drainage infrastructure is commonly known to be inadequate [32].

Table 2. Distribution of vegetation cover changes in relation to agricultural land-use changes in 1998 and 2010.

\begin{tabular}{|c|c|c|c|c|c|c|c|c|c|}
\hline \multirow{2}{*}{$\begin{array}{l}\text { Land Use Changes } \\
\qquad(1998-2010)\end{array}$} & \multicolumn{3}{|c|}{ Vegetation Cover Decrease } & \multicolumn{3}{|c|}{ Vegetation Cover Increase } & \multicolumn{3}{|c|}{ Persisting Conditions } \\
\hline & $\begin{array}{l}\text { Number } \\
\text { of Fields }\end{array}$ & $\begin{array}{l}\text { Area } \\
\text { (ha) }\end{array}$ & $\begin{array}{c}\% \text { of } \\
\text { Irrigated Area }\end{array}$ & $\begin{array}{l}\text { Number } \\
\text { of Fields }\end{array}$ & $\begin{array}{l}\text { Area } \\
\text { (ha) }\end{array}$ & $\begin{array}{c}\% \text { of } \\
\text { Irrigated Area }\end{array}$ & $\begin{array}{l}\text { Number } \\
\text { of Fields }\end{array}$ & $\begin{array}{l}\text { Area } \\
\text { (ha) }\end{array}$ & $\begin{array}{c}\% \text { of } \\
\text { Irrigated Area }\end{array}$ \\
\hline $\begin{array}{l}\text { Cropped in } 1998 \text { and } \\
\text { cropped in } 2010\end{array}$ & 6532 & 26,773 & 27 & 4424 & 17,982 & 18 & 17,748 & 19,427 & 20 \\
\hline $\begin{array}{l}\text { Fallow in } 1998 \text { and } \\
\text { fallow in } 2010\end{array}$ & 402 & 1990 & 2 & 194 & 574 & 1 & 965 & 3788 & 4 \\
\hline $\begin{array}{l}\text { Cropped in } 1998 \text { and } \\
\text { fallow in } 2010\end{array}$ & 764 & 7049 & 7 & 382 & 1405 & 1 & 1779 & 3442 & 3 \\
\hline $\begin{array}{l}\text { Fallow in } 1998 \text { and } \\
\text { cropped in } 2010\end{array}$ & 510 & 1860 & 2 & 1443 & 4816 & 5 & 2536 & 10,227 & 10 \\
\hline TOTAL & 8208 & 37,672 & 38 & 6443 & 24,777 & 25 & 23,028 & 36,884 & 37 \\
\hline
\end{tabular}

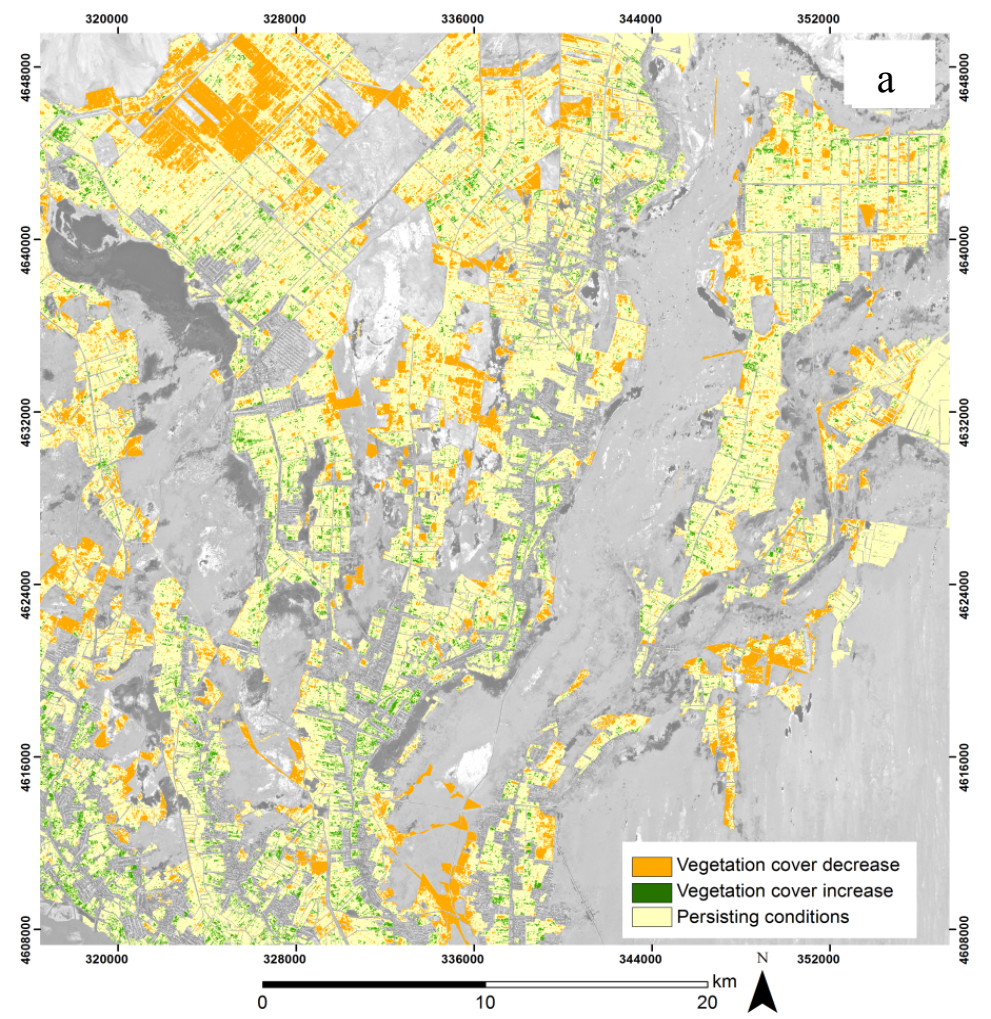

Figure 4. Cont. 

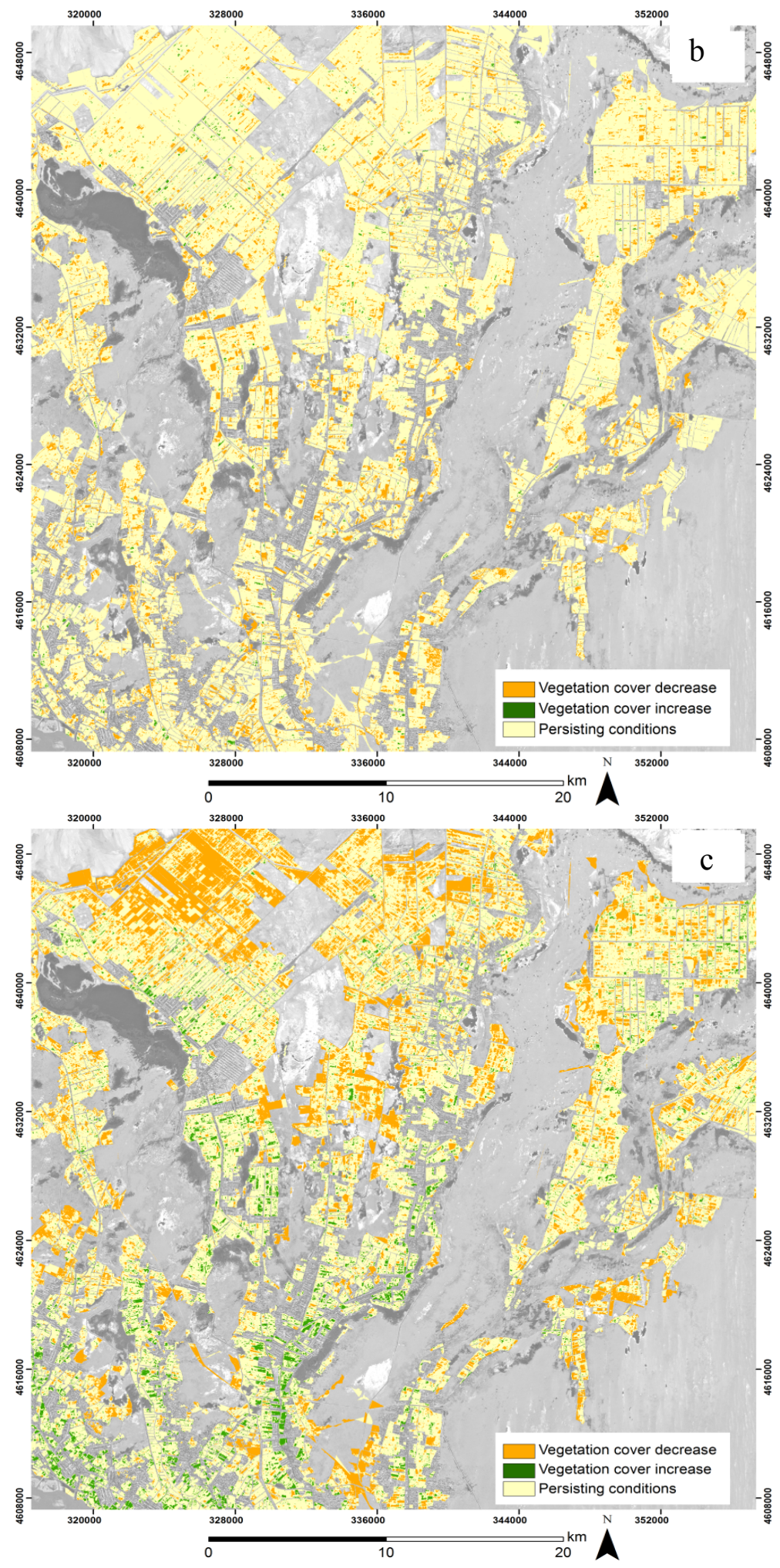

Figure 4. Results of change vector analysis based on the fraction images calculated from multitemporal $10 \mathrm{~m}$ SPOT data: (a) Overall change direction map for the years 1998-2010; (b) Change direction map for the years 2006-2010; (c) Change direction map for the years. 1998-2006. 


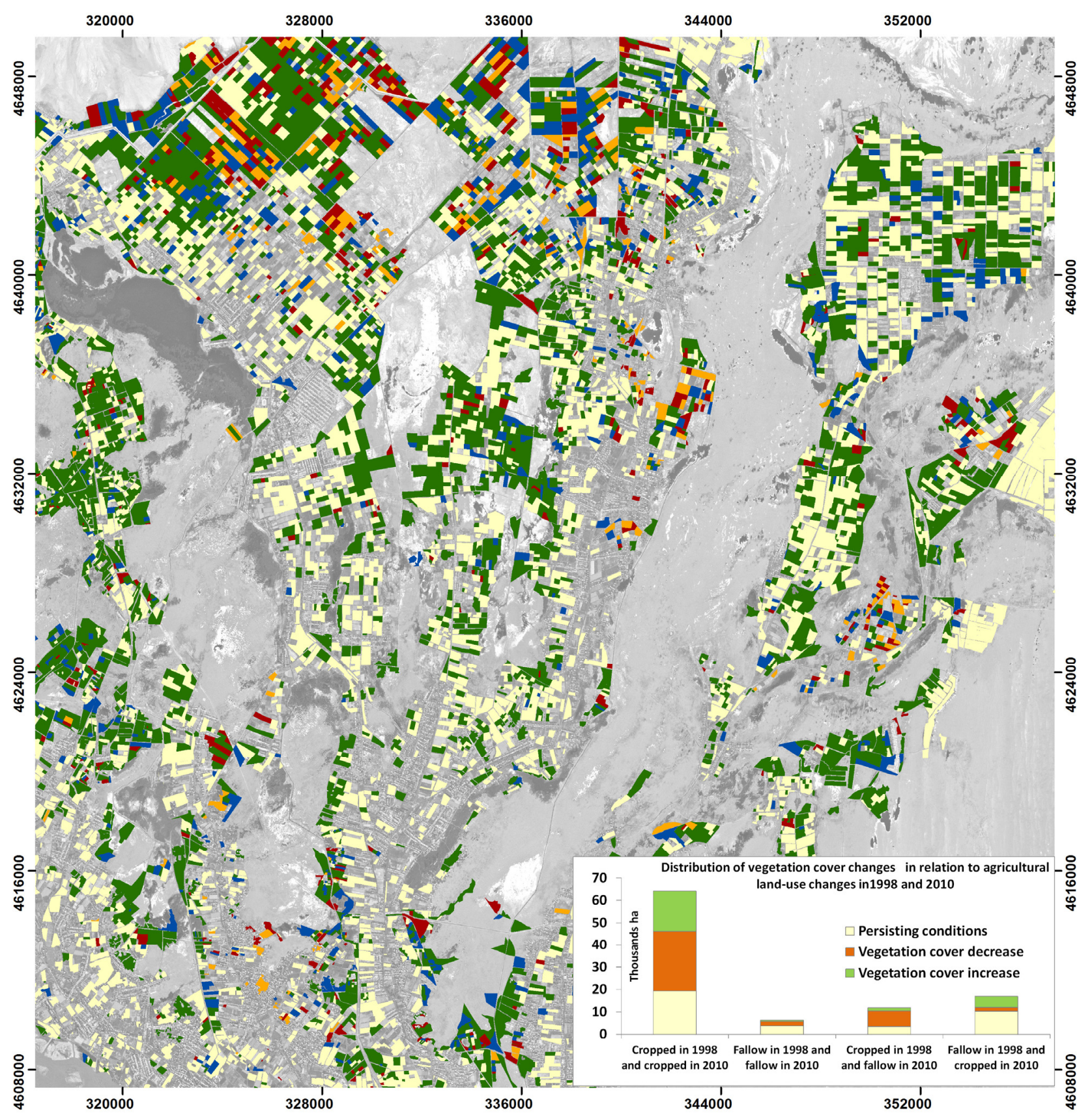

\section{Vegetation cover decrease in relation to land-use changes in 1998 and 2010}

Cropped in 1998 and cropped in $2010 \square$ Other changes (vegetation increase and persisting conditions)

Fallow in 1998 and fallow in 2010

Cropped in 1998 and fallow in 2010

Fallow in 1998 and cropped in 2010

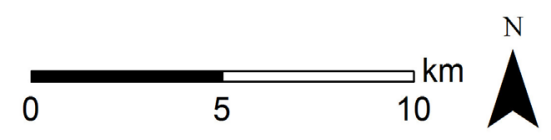

Figure 5. Spatial distribution of field parcels with decreased vegetation cover in relation to land-use changes between 1998 and 2010.

CVA results show that the majority of regional vegetation cover changes occurred during the period between 1998 and 2006. Persistent vegetation conditions were prevalent during 2006-2010 in the study area (Figure 4b,c). Beginning in 1991, restructuring of the agricultural system has taken place in Uzbekistan. During the initial phase of this process (1991-1998), the principal agricultural production 
units established during the Soviet era-large collective farms called kolhozes-were generally preserved [67]. The second and the third phases of farm restructuring took place in 1998-2003 and 2003-2008, and a number of significant changes occurred during these years. Numerous kolkhozes were transformed into agricultural cooperatives called shirkats, large farm operations were fragmented and private farms were initiated. Most of the changes in cropping patterns in the study region thus occurred after 1998, as these more commercially oriented private farms began emphasizing the production of cash crops such as rice. The area under winter wheat has significantly increased in the region since the year 2000 in an effort to achieve the state mandated goal of grain self-sufficiency. This increase in wheat cultivation has displaced a portion of fodder crop production [68]. As these changes have taken place, however, the state commitment to the cultivation of cotton and winter wheat has continued and high productivity cropland areas have been reserved for these strategic crops since 1991 [67]. It is important to understand this background in combination with a number of additional factors, including the system of area-based state crop mandates, the standard production guidelines for crop irrigation and fertilizer application and the adequate water supplies in place in 1998 and 2010. The 2010 regional crop cover decline observed in the cotton and winter wheat growing areas should therefore be attributed to LD, rather than to any reduction in agricultural inputs in these areas (Figures 2 and 5).

The decreased vegetation cover observed on the land left fallow in 1998 and 2010 (Table 2; Figure 5) are likely a result of overgrazing of the natural vegetation as herding livestock on uncultivated cropland areas is a common practice in the SKKP [69]. The reduced vegetative cover apparent in previously fallow lands that have been returned to cultivation in 2010 may be explained by the pre-cropping clearance of halophytic shrubs and grass that tend to dominate long-term fallowed areas. Causes of the vegetation cover decline observed in the remaining 15,247 ha of cropping area in the region must be verified through further in situ field investigation. Attention should be directed at both LD processes such as soil salinization as well as changes in agricultural management practices [70].

\subsection{Evaluation of the Change Detection Results}

The overall 1998-2010 change direction map indicates an agreement of $84 \%$ with the MODIS-based LD trend map. This reinforces the effectiveness of the CVA-SMA analytic approach in identifying lands affected by a significant vegetation cover decline. For the "other trends" map class, producer's accuracy was calculated at $82 \%$, with user's accuracy at $91 \%$. This strongly suggests that the two maps are in overall agreement for this class. Both of these metrics were lower for the "LD" class, however (producer's accuracy $=69 \%$; user's accuracy $=62 \%$ ). This underestimation of vegetation cover decline in both change maps highlights a disadvantage of applying bi- or multi-temporal change detection procedures rather than trend analyses, which monitor gradual land cover processes based on continuous information from satellite time series data [71]. Trend analysis, on the other hand, depends upon the availability of high spatial resolution image time series data, which is not available for all regions of the world, including Central Asia [22].

The CVA approach has been shown to be effective and accurate for mapping land cover changes within managed and naturally arid landscapes at high spatial detail $[28,29]$. Although SPOT imagery is effective for land cover change detection in a number of applications, a multi-resolution approach that combines both coarse and fine scale data sets is more effective for characterization of vegetation dynamics in 
irrigated cropland environments as described here. Fundamentally, it should be noted that the general approach based on vegetation monitoring applied in this research is currently the only operational LD analytic methodology which may be effectively implemented across extensive areas [72-74].

The types of change maps produced in this study must also be interpreted with care, preferably in conjunction with ancillary data such as the agricultural land use maps used in this work. Secondary datasets and expert knowledge are very important for the identification of environmental and land management issues (particularly for irrigated lands) that may be integral to the agricultural system. In the SKKP study area, reduced cropland productivity as reflected in losses of vegetation cover through time can be attributed to LD resulting from soil salinization as well as interruptions in cropping activity. Whether vegetation cover loss may be attributed to deteriorating soil conditions or decreased cultivation (or a combination of the two), it represents a decline in the economic productivity of irrigated croplands and a decrease in their overall productive function [23]. The developed approach is deemed suitable for irrigated croplands of post-soviet Central Asia where irrigated agricultural land management and cultivation patterns as well as associated LD problems are similar. The applicability of the same approach outside this region should be further tested.

\subsection{Implications for Site-Specific Cropland Management}

The use of very high $10 \mathrm{~m}$ spatial resolution SPOT imagery within the context of the CVA-SMA analytic approach enabled us to characterize specific conditions within the SKKP study site at very high levels of spatial detail. This allowed information to be gathered and evaluated regarding regional agricultural irrigation and leaching applications and thus to make practical contributions to water saving practices [31]. The combined CVA-SMA procedure identified within-field vegetation cover variability, as shown in Figure 6 (left and middle columns) and may by compared to the traditional whole-field approach (Figure 6, right column). If identical agricultural inputs are assumed across the fields, the observed differences in crop performance must be a function of soil salinity and the variability identified within the fields indicates inefficient management of this problem [3].

Management of soil salinity could be significantly improved by refining land leveling operations. In particular, the use of laser guided devices prior to salt leaching would allow more uniform microtopography and water distribution within fields and enhance the salt management efficiency [31]. Additional research should focus on linking our findings to in situ soil salinity measurements, using, for example, electromagnetic induction measurements. Volumes of water required for salt leaching can be significantly reduced by site-specific targeting that quantifies actual soil salinity in the crop root-zone [3].

The availability of sub-field information on soil and crop conditions should also allow reductions in excessive nitrogen fertilizer inputs by focusing applications on areas of greatest need, thus helping to optimize yields [75]. The subsequent reduction in percolation of nitrogen fertilizers down to the groundwater table would also decrease the environmental pollution associated with intensive agriculture. Further refinement of the CVA-SMA approach tested here should proceed in close cooperation with local agricultural planners, land managers, and scientists to accommodate local needs and to assure applicability of results. It is also important to conduct additional ground measurements in the SKKP study region in order to further validate our results and to establish a suite of quantitative in situ data. 


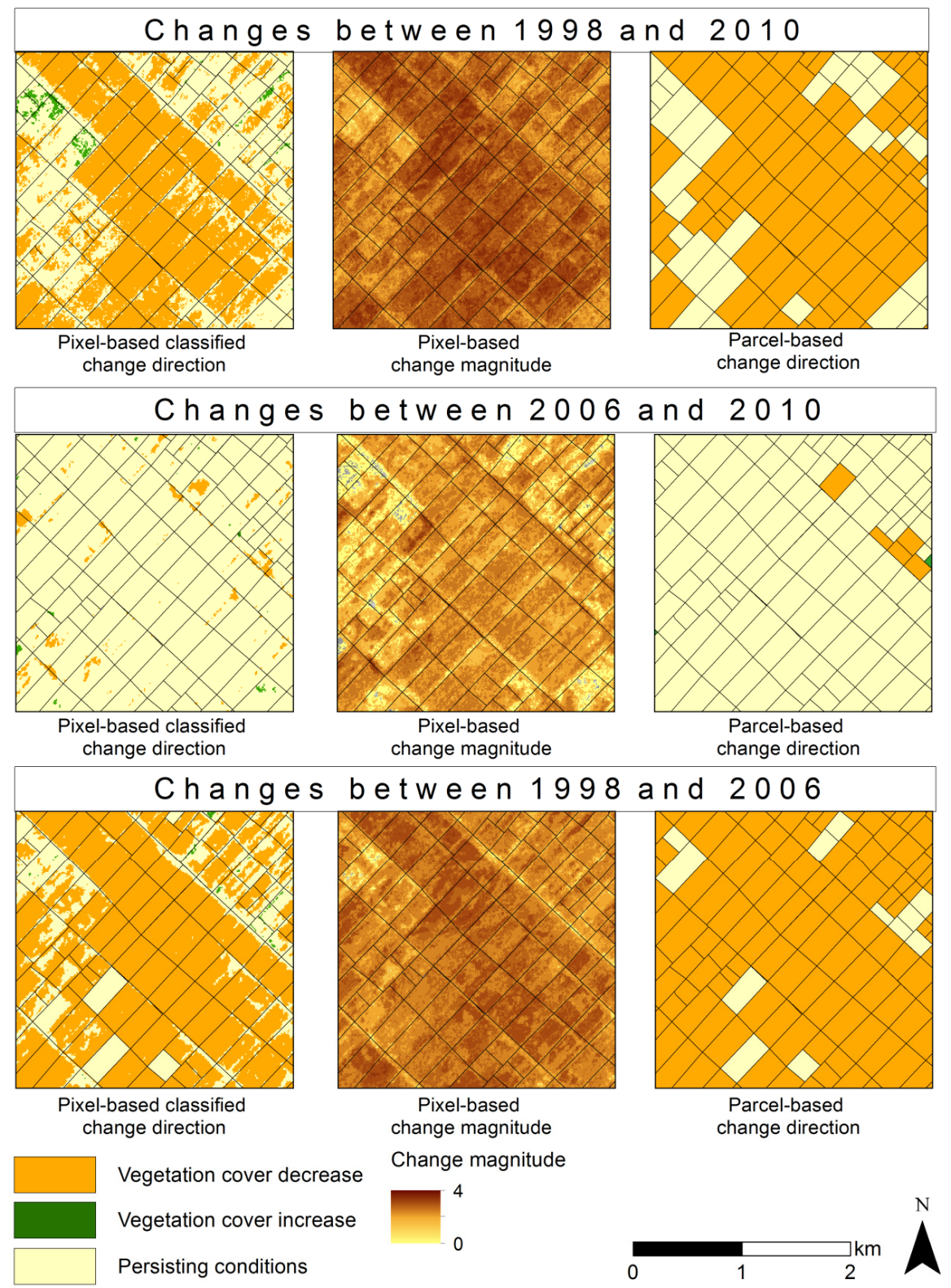

Figure 6. Subsets of the change direction maps (left column) and change magnitude images (middle column) showing sub-field pixel-wise changes of vegetation cover and object-based change direction maps.

\section{Conclusions}

Irrigated agro-ecosystems in Central Asian drylands have experienced an observable decline in cropland productivity and overall high within-field heterogeneity in crop performance. Considering the importance of maps availability to support sustainable land management as well as land restoration efforts, this research bridged a current gap by providing spatially-explicit sub-field information on land cover changes for the irrigated lowlands of the Amu Darya River in Uzbekistan. This paper also contributes to the development of methods that will support future assessments in similar landscapes via elaborating a combined change vector analysis and spectral unmixing (CVA-SMA) procedure based on multitemporal high spatial resolution (10 m) SPOT imagery. 
Overall, our results confirmed the utility of the SPOT data as well as proposed combined CVA-SMA procedure for monitoring crop cover dynamics at sub-field and field level in the study area. Inter-annual crop cover changes during the period of 1998-2010 were driven by a complex set of interrelated environmental factors, including harsh climatic conditions, poor or fragile soils, micro-topography and location. These variables also impacted land management decisions and longterm agricultural planning. Within this context, the vegetation cover changes that were identified in the study area generally reflect to certain extent the farm restructuring processes that started in Uzbekistan after independence in 1991. We conclude, however, that the declines in cropland cover that were identified in this study can be more directly attributed to the impact of regional soil salinity conditions. Excess soil salinity affects crop growth and precludes farmers from cropping in areas where salinity levels are unmanageable. In addition, problems of secondary soil salinization are also a consequence of long-term land and irrigation water mismanagement in the study area which have been ongoing since the 1950 s era.

The approach described here may be implemented in additional cases where spatial information is required at scales appropriate for site-specific management interventions in such activities as irrigation, salt leaching, and fertilizer applications. The high level of spatial detail makes such spatial information useful at the individual sub-field level. Further research should focus on linking these high spatial resolution remote sensing approaches with in situ measurements to support their acceptance and utilization in precision agriculture.

\section{Acknowledgments}

The authors gratefully acknowledge the support of the Robert Bosch Foundation for supporting this study within the framework of the project "Opportunities for Climate Change Mitigation Through Afforestation of Degraded Lands in Central Asia". We are grateful to the Planet Action initiative for providing SPOT images as a part of the project "Land and Water Management in Central Asia". We also acknowledge the contribution of Mr. Joseph Scepan of Medford, Oregon, USA, in producing this document. We would like also to acknowledge the help of four reviewers for improving of this manuscript.

\section{Author Contributions}

Olena Dubovyk framed the study, performed the analysis and authored the primary manuscript. Alexander Lee contributed to analysis and data collection. All authors contributed to conceptual discussions, the interpretation of results and commented on the manuscript.

\section{Conflicts of Interest}

The authors declare no conflict of interest.

\section{References}

1. Kienzler, K.M.; Lamers, J.P.A.; McDonald, A.; Mirzabaev, A.; Ibragimov, N.; Egamberdiev, O.; Ruzibaev, E.; Akramkhanov, A. Conservation agriculture in Central Asia-What do we know and where do we go from here? Field Crop. Res. 2012, 132, 95-105. 
2. Bucknall, J.; Klytchnikova, I.; Lampietti, J.; Lundell, M.; Scatasta, M.; Thurman, M. Irrigation in Central Asia: Social, Economic and Environmental Considerations; World Bank: Washington, DC, USA, 2003.

3. Akramkhanov, A.; Brus, D.J.; Walvoort, D.J.J. Geostatistical monitoring of soil salinity in Uzbekistan by repeated EMI surveys. Geoderma 2014, 213, 600-607.

4. Ji, C. Central Asian Countries Initiative for Land Management Multicountry Partnership Framework Support Project; ADB: Tashkent, Uzbekistan, 2008.

5. Dubovyk, O.; Menz, G.; Khamzina, A. Land suitability assessment for afforestation with Elaeagnus angustifolia L. In degraded agricultural areas of the lower Amu Darya river basin. Land Degrad. Dev. 2014, doi: 10.1002/ldr.2329.

6. Le, Q.B.; Tamene, L.; Vlek, P.L.G. Multi-pronged assessment of land degradation in West Africa to assess the importance of atmospheric fertilization in masking the processes involved. Glob. Planet. Chang. 2012, 92-93, 71-81.

7. Karnieli, A.; Bayarjargal, Y.; Bayasgalan, M.; Mandakh, B.; Dugarjav, C.; Burgheimer, J.; Khudulmur, S.; Bazha, S.N.; Gunin, P.D. Do vegetation indices provide a reliable indication of vegetation degradation? A case study in the Mongolian pastures. Int. J. Remote Sens. 2013, $34,6243-6262$.

8. Chen, X.; Bai, J.; Li, X.; Luo, G.; Li, J.; Li, B.L. Changes in land use/land cover and ecosystem services in Central Asia during 1990-2009. Curr. Opin. Environ. Sustain. 2013, 5, 116-127.

9. Conrad, C.; Dech, S.; Dubovyk, O.; Fritsch, S.; Klein, D.; Löw, F.; Schorcht, G.; Zeidler, J. Derivation of temporal windows for accurate crop discrimination in heterogeneous croplands of Uzbekistan using multitemporal RapidEye images. Comput. Electron. Agric. 2014, 103, 63-74.

10. Klein, I.; Gessner, U.; Künzer, C. Generation of up to date land cover maps for Central Asia. In Novel Measurement and Assessment Tools for Monitoring and Management of Land and Water Resources in Agricultural Landscapes of Central Asia; Mueller, L., Saparov, A., Lischeid, G., Eds.; Springer International Publishing: Cham, Switzerland, 2014; pp. 329-346.

11. Karnieli, A.; Gilad, U.; Ponzet, M.; Svoray, T.; Mirzadinov, R.; Fedorina, O. Assessing land-cover change and degradation in the Central Asian deserts using satellite image processing and geostatistical methods. J. Arid Environ. 2008, 72, 2093-2105.

12. Propastin, P.A.; Kappas, M.; Muratova, N.R. Inter-annual changes in vegetation activities and their relationship to temperature and precipitation in Central Asia from 1982 to 2003. J. Environ. Inform. 2008, 12, 75-87.

13. De Beurs, K.M.; Henebry, G.M. Land surface phenology, climatic variation, and institutional change: Analyzing agricultural land cover change in Kazakhstan. Remote Sens. Environ. 2004, 89, 497-509.

14. Dubovyk, O.; Menz, G.; Conrad, C.; Lamers, J.; Lee, A.; Khamzina, A. Spatial targeting of land rehabilitation: A relational analysis of cropland productivity decline in arid Uzbekistan. Erdkunde 2013, 67, 167-181.

15. Tüshaus, J.; Dubovyk, O.; Khamzina, A.; Menz, G. Comparison of medium spatial resolution ENVISAT-MERIS and Terra-MODIS time series for vegetation decline analysis: A case study in Central Asia. Remote Sens. 2014, 6, 5238-5256.

16. Le, Q.B.; Nkonya, E.; Mirzabaev, A. Biomass Productivity-Based Mapping of Global Land Degradation Hotspots; Center for Development Research (ZEF): Bonn, Germany, 2014. 
17. Castillejo-González, I.L.; Peña-Barragán, J.M.; Jurado-Expósito, M.; Mesas-Carrascosa, F.J.; López-Granados, F. Evaluation of pixel- and object-based approaches for mapping wild oat (Avena sterilis) weed patches in wheat fields using QuickBird imagery for site-specific management. Eur. J. Agron. 2014, 59, 57-66.

18. Reynolds, J.; Smith, D.; Lambin, E.; Turner, B.; Mortimore, M.; Batterbury, S.; Downing, T.; Dowlatabadi, H.; Fernandez, R.; Herrick, J.; et al. Global desertification: Building a science for dryland development. Science 2007, 316, 847-851.

19. Li, Z.; Huffman, T.; McConkey, B.; Townley-Smith, L. Monitoring and modeling spatial and temporal patterns of grassland dynamics using time-series MODIS NDVI with climate and stocking data. Remote Sens. Environ. 2013, 138, 232-244.

20. Bai, Z.G.; Dent, D.L.; Olsson, L.; Schaepman, M.E. Proxy global assessment of land degradation. Soil Use Manag. 2008, 24, 223-234.

21. Röder, A.; Udelhoven, T.; Hill, J.; del Barrio, G.; Tsiourlis, G. Trend analysis of Landsat-TM and -ETM+ imagery to monitor grazing impact in a rangeland ecosystem in northern Greece. Remote Sens. Environ. 2008, 112, 2863-2875.

22. Kovalskyy, V.; Roy, D.P. The global availability of Landsat 5 TM and Landsat 7 ETM+ land surface observations and implications for global $30 \mathrm{~m}$ Landsat data product generation. Remote Sens. Environ. 2013, 130, 280-293.

23. Dubovyk, O.; Menz, G.; Conrad, C.; Thonfeld, F.; Khamzina, A. Object-based identification of vegetation cover decline in irrigated agro-ecosystems in Uzbekistan. Q. Int. 2013, 311, 163-174.

24. Malila, W.A. Change vector analysis: An approach for detecting forest changes with Landsat. In Proceedings of The 6th Annual Symposium on Machine Processing of Remotely Sensed Data, West Lafayette, IN, USA, 3-6 June 1980; Purdue University Press: West Lafayette, IN, USA, 1980; pp. 326-335.

25. Johnson, R.D.; Kasischke, E.S. Change vector analysis: A technique for the multispectral monitoring of land cover and condition. Int. J. Remote Sens. 1998, 19, 411-426.

26. Landmann, T.; Schramm, M.; Huettich, C.; Dech, S. MODIS-based change vector analysis for assessing wetland dynamics in southern Africa. Remote Sens. Lett. 2012, 1-10.

27. He, C.; Wei, A.; Shi, P.; Zhang, Q.; Zhao, Y. Detecting land-use/land-cover change in rural-urban fringe areas using extended change-vector analysis. Int. J. Appl. Earth Obs. Geoinf. 2011, 13, 572-585.

28. Karnieli, A.; Qin, Z.; Wu, B.; Panov, N.; Yan, F. Spatio-temporal dynamics of land-use and land-cover in the Mu Us sandy land, China, using the change vector analysis technique. Remote Sens. 2014, 6, 9316-9339.

29. Dawelbait, M.; Morari, F. Monitoring desertification in a savannah region in Sudan using Landsat images and spectral mixture analysis. J. Arid Environ. 2012, 80, 45-55.

30. Glazirin, G.E.; Chanishev, S.G.; Chub, V.E. Brief Outlines of Climate in Uzbekistan; Chinor ENK: Tashkent, Uzbekistan, 1999. (In Russian)

31. Tischbein, B.; Awan, U.K.; Abdullaev, I.; Bobojonov, I.; Conrad, C.; Jabborov, H.; Forkutsa, I.; Ibrakhimov, M.; Poluasheva, G.; Martius, C.; et al. Water management in Khorezm: Current situation and options for improvement (hydrological perspective). In Cotton, Water, Salts and Soums; Martius, C., Rudenko, I., Lamers, J., Vlek, P., Eds.; Springer: Dordrecht, The Netherlands, 2012; pp. 69-92. 
32. Mott-MacDonald. South Karakalpakstan Water Resources Management Improvement Project: Feasibility Report for Ministry of Agriculture and Water Resources of Uzbekistan; Mott-MacDonald (World Bank): Tashkent, Uzbekistan, 2011.

33. Rakhimbaev, F.; Bezpalov, M.; Khamidov, M.; Isabaev, K.; Alieva, D. Peculiarities of Crop Irrigation in Lower Amu Darya River Areas; FAN: Tashkent, Uzbekistan, 1992.

34. Akramkhanov, A.; Martius, C.; Park, S.J.; Hendrickx, J.M.H. Environmental factors of spatial distribution of soil salinity on flat irrigated terrain. Geoderma 2011, 163, 55-62.

35. Pohl, C.; van Genderen, J.L. Review article multisensor image fusion in remote sensing: Concepts, methods and applications. Int. J. Remote Sens. 1998, 19, 823-854.

36. LeicaGeosystems. Imagine Autosync ${ }^{\mathrm{TM}}$ White Paper; Leica Geosystems Geospatial Imaging: Norcross, GA, USA, 2006.

37. Richter, R. Atmospheric/Topographic Correction for Satellite Imagery (Atcor-2/3 User Guide, Version 8.2 Beta, February 2012). Available online: http://www.dlr.de/eoc/Portaldata/60/Resources/ dokumente/5_tech_mod/atcor3_manual_2012.pdf(accessed on 20 May 2015).

38. Canty, M.J.; Nielsen, A.A. Automatic radiometric normalization of multitemporal satellite imagery with the iteratively re-weighted mad transformation. Remote Sens. Environ. 2008, 112, 1025-1036.

39. Scientific-Information Center of the Interstate Coordination Water Commission of the Central Asia (SIC-ICWC). Warmis Database. Available online: http://sic.icwc-aral.uz/index_e.htm (accessed on 20 May 2015).

40. Van Assche, K.; Djanibekov, N. Spatial planning as policy integration: The need for an evolutionary perspective. Lessons from Uzbekistan. Land Use Policy 2012, 29, 179-186.

41. Pena-Barragan, J.; Ngugi, M.K.; Plant, R.E.; Six, J. Object-based crop identification using multiple vegetation indices, textural features and crop phenology. Remote Sens. Environ. 2011, 115, 1301-1316.

42. Adams, J.B.; Smith, M.O.; Johnson, P.E. Spectral mixture modeling: A new analysis of rock and soil types at the Viking Lander 1 site. J. Geophys. Res. 1986, 91, 8098-8112.

43. Brisco, B.; Brown, R.J.; Hirose, T.; Mcnairn, H.; Staenz, K. Precision agriculture and the role of remote sensing: A review. Can. J. Remote Sens. 1998, 24, 315-327.

44. Asner, G.P.; Lobell, D.B. A biogeophysical approach for automated SWIR unmixing of soils and vegetation. Remote Sens. Environ. 2000, 74, 99-112.

45. Chikhaoui, M.; Bonn, F.; Bokoye, A.I.; Merzouk, A. A spectral index for land degradation mapping using ASTER data: Application to a semi-arid Mediterranean catchment. Int. J. Appl. Earth Obs. Geoinf. 2005, 7, 140-153.

46. Plaza, A.; Martinez, P.; Perez, R.; Plaza, J. Spatial/spectral endmember extraction by multidimensional morphological operations. IEEE Trans. Geosci. Remote Sens. 2002, 40, 2025-2041.

47. Dennison, P.E.; Charoensiri, K.; Roberts, D.A.; Peterson, S.H.; Green, R.O. Wildfire temperature and land cover modeling using hyperspectral data. Remote Sens. Environ. 2006, 100, 212-222.

48. Lu, D.; Batistella, M.; Mausel, P.; Moran, E. Mapping and monitoring land degradation risks in the western Brazilian Amazon using multitemporal Landsat TM/ETM+ images. Land Degrad. Dev. 2007, 18, 41-54.

49. Green, A.A.; Berman, M.; Switzer, P.; Craig, M.D. A transformation for ordering multispectral data in terms of image quality with implications for noise removal. IEEE Trans. Geosci. Remote Sens. 1988, 26, 65-74. 
50. Boardman, J.W.; Kruse, F.A.; Green, R.O. Mapping target signatures via partial unmixing of Aviris data. In Proceeding of Fifth JPL Airborne Earth Science Workshop, Pasadena, CA, USA, 23-26 January 1995.

51. Zerger, A.; Warren, G.; Hill, P.; Robertson, D.; Weidemann, A.; Lawton, K. Multi-criteria assessment for linking regional conservation planning and farm-scale actions. Environ. Model. Softw. 2011, 26, 103-110.

52. Collado, A.; Chuvieco, E.; Camarasa, A. Satellite remote sensing analysis to monitor desertification processes in the crop-rangeland boundary of Argentina. J. Arid. Environ. 2002, 52, 121-133.

53. Elmore, A.J.; Mustard, J.F.; Manning, S.J.; Lobell, D.B. Quantifying vegetation change in semiarid environments-Precision and accuracy of spectral mixture analysis and the normalized difference vegetation index. Remote Sens. Environ. 2000, 73, 87-102.

54. Somers, B.; Asner, G.P.; Tits, L.; Coppin, P. Endmember variability in spectral mixture analysis: A review. Remote Sens. Environ. 2011, 115, 1603-1616.

55. Roberts, D.A.; Gardner, M.; Church, R.; Ustin, S.; Scheer, G.; Green, R.O. Mapping chaparral in the Santa Monica mountains using multiple endmember spectral mixture models. Remote Sens. Environ. 1998, 65, 267-279.

56. Rogerson, P.A. Change detection thresholds for remotely sensed images. J. Geogr. Syst. 2002, 4, 85-97.

57. Otsu, N. A threshold selection method from gray-level histograms. IEEE Trans. Man Cybern. Syst. 1979, 9, 62-66.

58. Rosin, P.L. Unimodal thresholding. Pattern Recognit. 2001, 34, 2083-2096.

59. Chen, J.; Gong, P.; He, C.; Pu, R.; Shi, P. Land-use/land-cover change detection using improved change-vector analysis. Photogramm. Eng. Remote Sens. 2003, 69, 369-379.

60. Gessner, U.; Machwitz, M.; Conrad, C.; Dech, S. Estimating the fractional cover of growth forms and bare surface in savannas. A multi-resolution approach based on regression tree ensembles. Remote Sens. Environ. 2013, 129, 90-102.

61. Dubovyk, O. Multi-Scale Targeting of Land Degradation in Northern Uzbekistan Using Satellite Remote Sensing. Ph.D. Thesis, University of Bonn, Bonn, Germany, 2013.

62. Dubovyk, O.; Conrad, C.; Khamzina, A.; Menz, G. Object-based retro-classification of agricultural land use: A case study of irrigated croplands. In Proceedings of 2013 ESA Living Planet Symposium (ESA SP-722), Edinburgh, UK, 9-13 September 2013.

63. Quintano, C.; Fernandez-Manso, A.; Shimabukuro, Y.E.; Pereira, G. Spectral unmixing. Int. J. Remote Sens. 2012, 33, 5307-5340.

64. Trodd, N.M.; Dougill, A.J. Monitoring vegetation dynamics in semi-arid african rangelands: Use and limitations of Earth observation data to characterize vegetation structure. Appl. Geogr. 1998, 18, 315-330.

65. Dubovyk, O.; Menz, G.; Conrad, C.; Khamzina, A. Object-based cropland degradation identification: A case study in Uzbekistan. Proc. SPIE 2012, doi: 10.1117/12.974647.

66. Djanibekov, N.; Rudenko, I.; Lamers, J.; Bobojonov, I. Pros and cons of cotton production in Uzbekistan. In Food Policy for Developing Countries: Food Production and Supply Policie, Pinstrup-Andersen, P., Cheng, F., Eds.; Cornell University Press: Ithaca, Greece, 2010; pp. 13-27. 
67. Djanibekov, N.; Bobojonov, I.; Lamers, J.A. Farm reform in Uzbekistan. In Cotton, Water, Salts and Soums; Martius, C., Rudenko, I., Lamers, J.P.A., Vlek, P.L.G., Eds.; Springer Netherlands: Dordrecht, The Netherlands, 2012; pp. 95-112.

68. Pomfret, R. Agrarian reform in Uzbekistan: Why has the Chinese model failed to deliver? Econ. Dev. Cult. Chang. 2000, 48, 269-284.

69. Djanibekov, N. Livestock system in households of Khorezm region. J. Uzb. Agric. 2006, 4, 1-10. (In Russian)

70. Akramkhanov, A.; Vlek, P.G. The assessment of spatial distribution of soil salinity risk using neural network. Environ. Monit. Assess. 2012, 184, 2475-2485.

71. Sonnenschein, R.; Kuemmerle, T.; Udelhoven, T.; Stellmes, M.; Hostert, P. Differences in landsat-based trend analyses in drylands due to the choice of vegetation estimate. Remote Sens. Environ. 2011, 115, 1408-1420.

72. Vogt, J.V.; Safriel, U.; Von Maltitz, G.; Sokona, Y.; Zougmore, R.; Bastin, G.; Hill, J. Monitoring and assessment of land degradation and desertification: Towards new conceptual and integrated approaches. Land Degrad. Dev. 2011, 22, 150-165.

73. Landmann, T.; Dubovyk, O. Mapping vegetation productivity dynamics and degradation trends over East Africa using a decade of medium resolution MODIS time-series data. In Proceedings of 2013 IEEE International Geoscience and Remote Sensing Symposium (IGARSS), Melbourne, VIC, Australia, 21-26 July 2013; pp. 1801-1804.

74. Wessels, K.J.; van den Bergh, F.; Scholes, R.J. Limits to detectability of land degradation by trend analysis of vegetation index data. Remote Sens. Environ. 2012, 125, 10-22.

75. Djanibekov, N.; Sommer, R.; Djanibekov, U. Evaluation of effects of cotton policy changes on land and water use in Uzbekistan: Application of a bio-economic farm model at the level of a water users association. Agric. Syst. 2013, 118, 1-13.

(C) 2015 by the authors; licensee MDPI, Basel, Switzerland. This article is an open access article distributed under the terms and conditions of the Creative Commons Attribution license (http://creativecommons.org/licenses/by/4.0/). 